\title{
Yangına Müdahale Tekniklerinde ve Yangın Teçhizatlarında Organizasyonel/Teknolojik İnovasyon
}

\author{
${ }^{*}$ Salim TURHAN, ${ }^{4}$ Orhan Oduncu, ${ }^{2,3}$ Hakan Serhad SOYHAN, ${ }^{4}$ Bülent AÇIL, ${ }^{4,5}$ Gökhan COŞKUN \\ ${ }^{1}$ İstanbul Aydın Üniversitesi, Fen Bilimleri Enstitütüsü, İş Sağlığı ve Güvenliği Ana Bilim Dalı, İSG Bölümü \\ (Mezun) İstanbul / Türkiye \\ ${ }^{2}$ Sakarya Üniversitesi, Yangın Araştırma ve Uygulama Merkezi, Esentepe Kampüsü, Sakarya. \\ ${ }^{3}$ Team-San, Esentepe Mah. Akademi Yolu Sok. Teknoloji Geliştirme Bölg. A Blok No:10A/B11, 54187, Sakarya. \\ ${ }^{4}$ Sakarya Üniversitesi Yangın güvenliği ve Yanma ABD \\ ${ }^{5}$ Sakarya Üniversitesi Makina Mühendisliği Serdivan/Sakarya
}

\section{Özet}

Sözlük anlamı yenilik olan inovasyon "Yeni fikirlerin, süreçlerin, ürünlerin ve hizmetlerin üretilmesi, kabul görmesi ve uygulamaya alınması" olarak tanımlamaktadır. İnovasyon, yeniliklere ve gelişmelere açık olmayı gerektirir. Yangın teknolojisinde her geçen gün yenilikler artmaktadır. Bu gelişmelere açık olan ve yakından takip eden yerel yönetimler itfaiyelerini güçlendirmekle birlikte daha güvenli şehirlerin ve sanayi alanlarının oluşmasınada imkan sağlamış olmaktadır. Bu çalışmada yangın müdahale teknikleri konusunda yeni teknik ve teknolojiler incelenmiştir.

Anahrar Kelimeler: Organizasyonel, teknolojik, inovasyon, yangına müdahale

\begin{abstract}
Glossary innovation is defined as innovation as "the generation, acceptance and application of new ideas, processes, products and services". Innovation requires openness to innovations and developments. Innovation is increasing day by day in fire technology. Local governments that are open and closely following these developments have strengthened their firefighting, as well as allowing for the creation of safer cities and industrial areas.
\end{abstract}

Key words: Organizational, technological, innovation, fire intervention

\section{Giriş}

İnovasyon latince bir sözcük olan “innovatus”tan çıkartım ile türetilmiştir. Türkçe'de” yenilikçilik” ve "yenilik" anlamında kullanılmaktadır. İnovasyon, sadelikten uzak tekdüzelik sınırları içerisinde olmayan farklı bir bakış açısı ile yeni fikirlerin türetilmesi ve bunların fiiliyata dökülmesidir. Ürün, hizmet, süreç, pazarlama ve organizasyonel inovasyon olarak türleri bulunmaktadır [2]. $\mathrm{Bu}$ çalışmada; Yangına Müdahale Tekniklerinde ve Yangın Teçhizatlarında organizasyonel ve teknolojik inovasyon kavramları hakkında bilgilere yer verilmektedir.-

*Corresponding author: Address: İstanbul Aydın Üniversitesi, Fen Bilimleri Enstitütüsü, İş Sağlığ1 ve Güvenliği Ana Bilim Dalı, İSG Bölümü (Mezun) İstanbul / Türkiye E-mail address: salimturhan@gmail.com, Phone: +905326548132 


\section{Yangına Müdahale Tekniklerinde İnovasyon}

Teknoloji günlük yaşamın vazgeçilmez bir parçası olarak her alanda gelişmektedir. Endüstriyel tesisler, üretim merkezleri, enerji tesisleri ve yüksek katlı yapılardaki yangın riski itfaiyecilik mesleğinin çağa ayak uydurmasını lüzumlu kılmaktadır. Yangına müdahale ve kontrol altına alma çalışmalarında yapay zeka itfaiyecilere yön vermeye başlamıştır

\subsection{Itfaiyecilikte Yapay Zeka}

Yapay zeka ile ilgili en son örneklerden biri, Nasa tarafindan yakın zaman içerisinde geliştirilmiştir. "Audrey" isimli projede itfaiyecilerin kuşandıkları yangına karşı koruyucu giysilerde bulunan sensörler vasıtasıyla itfaiyecilerin yapı içerisindeki yeri, bulunduğu ortamdaki sıcaklık seviyesi, toksik gazlar ve çeşitli kimyasalların tespiti yapılabilmektedir. Geliştirilmiş olan yapay zeka yazılımı sayesinde toplanan bilgiler değerlendirilmekte ve tehlikelerle ilgili tahminler mahalde bulunan itfaiyeciye aktarılarak yönlendirme yapılabilmektedir. Yeni sistem (şekil 1-2) aynı zamanda yangın bölgesinin tehlike haritasını çıkartarak meydana gelebilecek tavan çökmesi, patlama riski gibi faktörlerde öngörülmektedir. Birleşik devletlerde geçen yıl 68 itfaiyecinin ölümüyle sonuçlanan yüksek riskli yangınlardaki bu ölümlerin minimize edilmesinin planlandığı bu yazılım ve kıyafet birkaç yıl içerisinde kullanılması öngörülmektedir [3] [4].

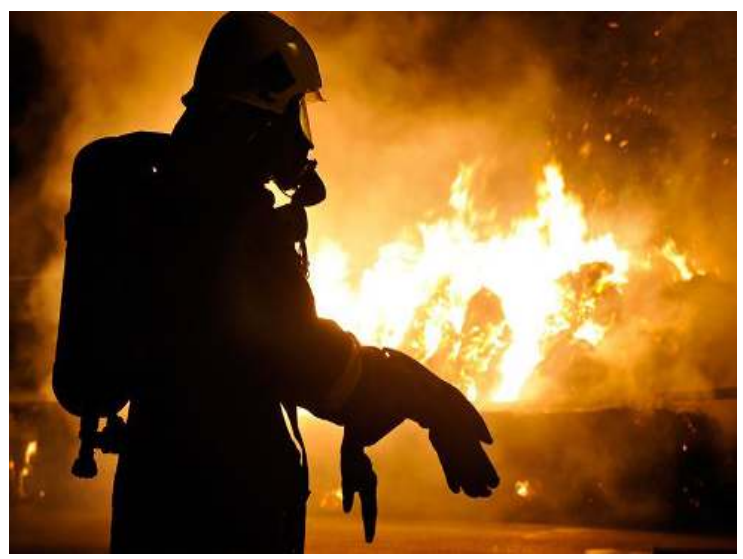

Şekil 1.Sensörlü itfaiyeci elbiseleri [3]

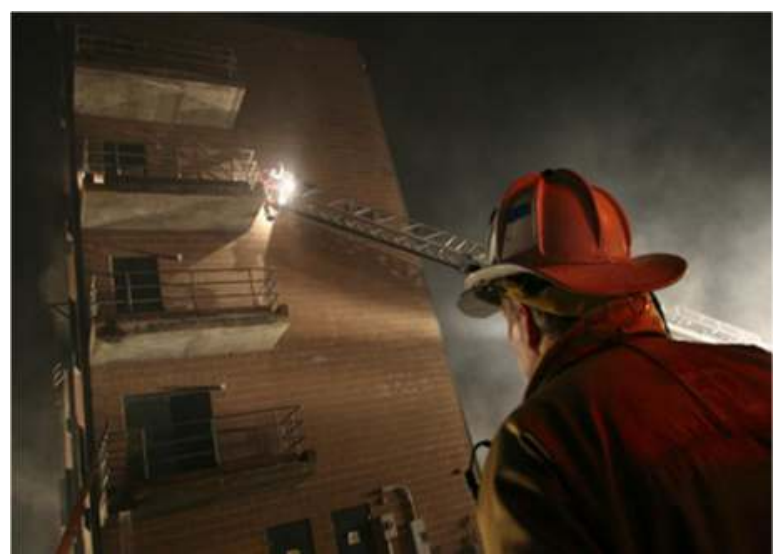

Şekil 2. Kapalı alanlardaki tehlike [4] 


\subsection{Acil Durumlarda Robot Yönlendirmeleri}

Acil durumlarda yapı içerisinde bulunan insanlar farklı davranış biçimi sergileyebilmektedir. Acil durumlarda insanların acil çıkışlara yönlendirmesini yapacak robot teknolojisi ile pek çok sorunun cevabı aranmaktadır. (Şekil 3) Bunlardan biri insanların dumanlı sahada robotların acil durum yönlendirmelerine riayet ettiği gözlemlenmiştir. Bu araştırmada insanların robotların çoğu şeyi bildiklerini düşünmesi ve robot tarafından verilen talimatlara uyduğu algısı belirmiştir [5].

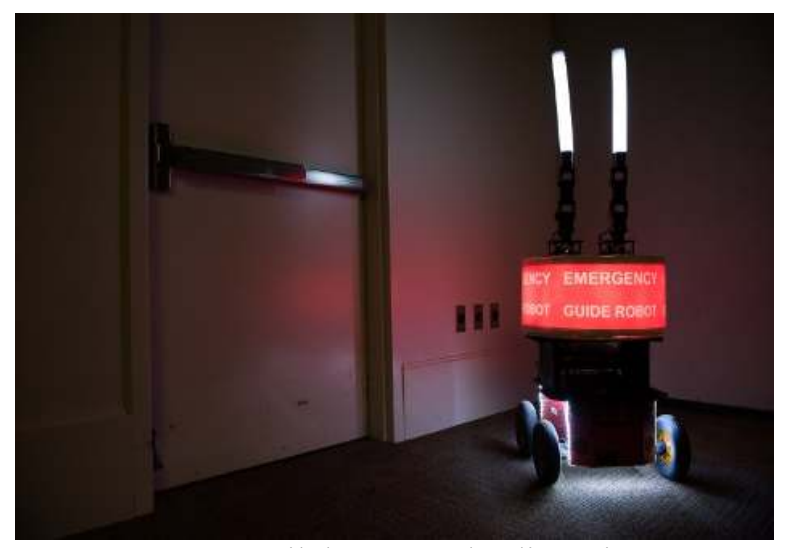

Şekil 3. Acil durum yönlendirmesi [5]

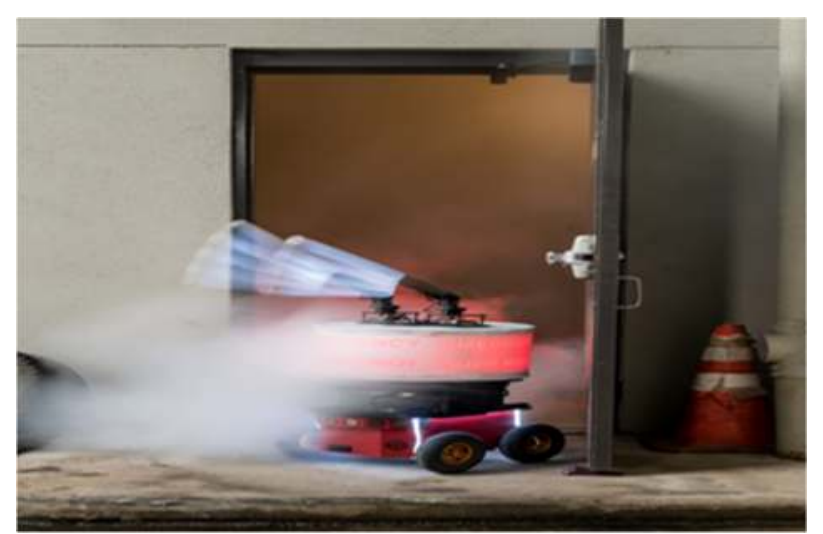

Şekil 4. Kurtarma Robotu” nun yangın anında sesli ve görsel ikazı [5]

\subsection{ABD Dz. Kuvvetleri Gemi Yangınları Söndürme Robotu}

Gemi yangınlarının karada çıkabilecek bir yangına göre daha tehlikeli olduğu bilinmektedir. Gemi aynı zamanda bir yaşam alanı iken diğer yandan diğer faaliyetlerin (askeri, ticari, kurtarma) yürütüldüğü ve insan sayısının gemi tiplerine göre çeşitlilik arz ettiği kapalı kompartmanlardan teşkil yüzer platformlardır. Şekil 5'te görüldüğü üzere Birleşik devletler donanması gemi yangınlarına müdahalede kullanılabilecek olan "Octavia" isimli robotu geliştirme evresinde. Kızılötesi kameralar ile donatılı Octavia sırtında bulundurduğu su tankına basınçlı hava ile su püskürtmesi yapabilmektedir [6] 


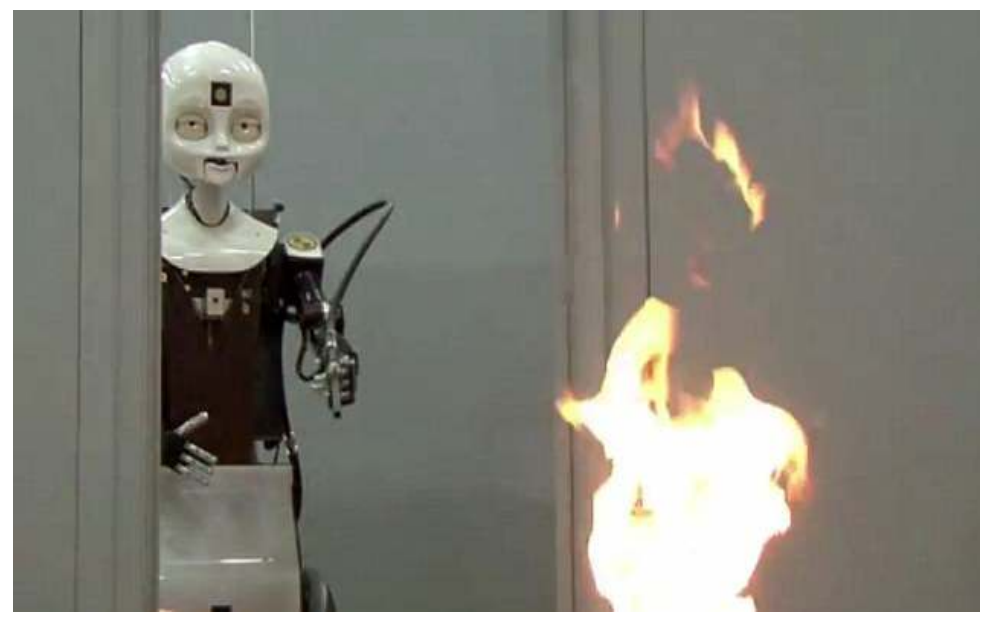

Şekil 5. Octavia robotu ile yangınla mücadele [6]

İnsan-robot etkileşiminin ürünlerinden biri olan Octavia'nın en son rakibi iki ayaklı bir robot olan "Saffir" dikkatleri üzerine çekmektedir. Burada amacın denizcileri, alevin doğrudan temasını engellemek olduğunu söyleyen tasarımcılar gemi içerisindeki 1s1 ölçümlerin, korozyon ve sızıntılarıda ölçebilecek kabiliyette olduğunu söylemektedir. (Şekil 6-7)

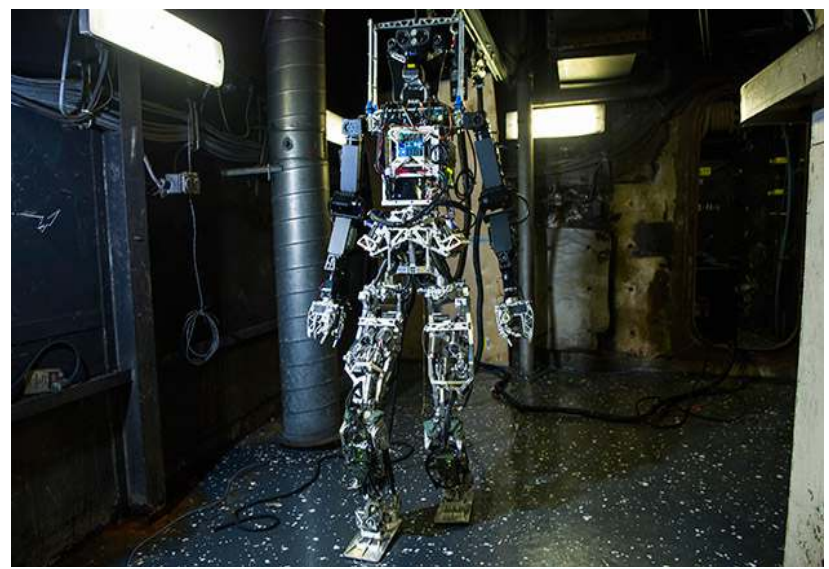

Resim 6. Saffir gemi içerisinde [7]

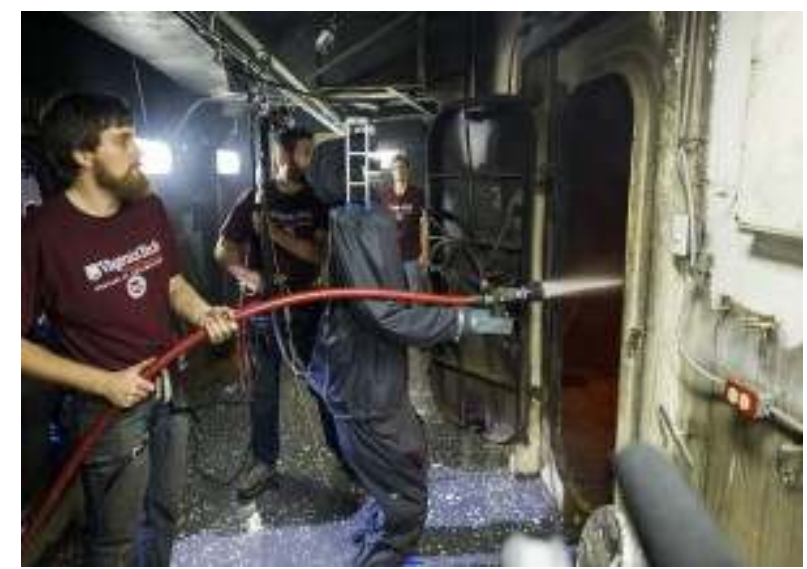

Resim 7. Saffir'in yangına müdahalesi [7] 
Girişimciler tüm bu verilerin gemi içerisinde kullanılabilecek bir dron (şekil 8'de örneği verilen) vasıtasıyla iki faktörlü bir uygulama ile de sağlanabileceğini ifade etmektedir [7].

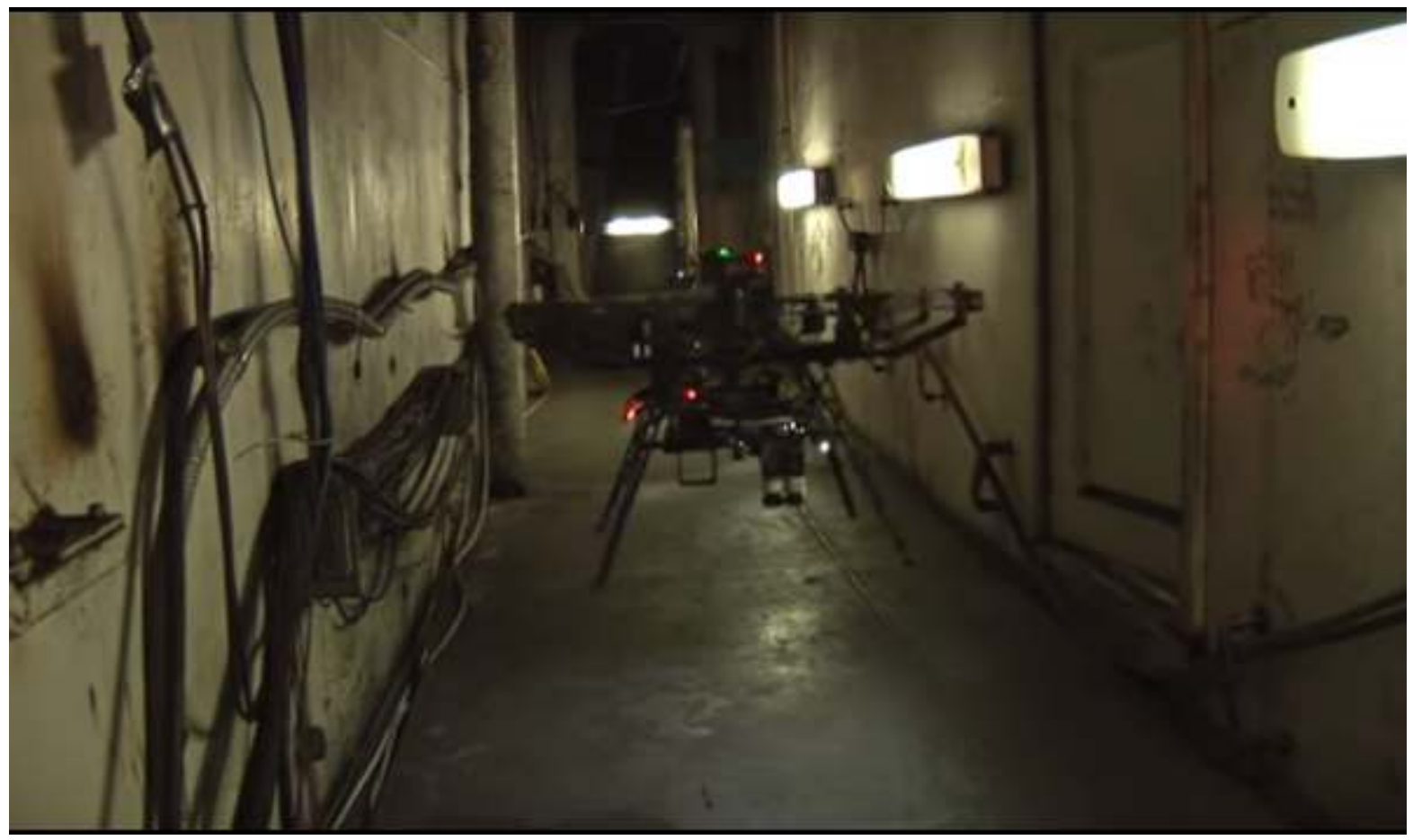

Şekil 8. Gemi içerisinde dron ile durum tespiti [7]

\subsection{Itfaiye Araçlarında Bulut Teknolojisi}

Acil durum olaylarının yönetimi profosyenellik gerektirdiği kadar üstün performans ve başarı odaklı olmalıdır. Yangın anında itfaiyeciler arasında etkili ve doğru bir iletişim önemli hale gelmektedir. İtfaiye araçlarında wifi teknolojisinin kullanımı hem personelin güvenliği ve hemde operasyonel başarıyı getirmektedir. Merkezi kumanda birimi araçların hangi istikamette ne kadar hızla gittiği yangın yerine ulaşımın en kolay yoldan itfaiye aracına nakil edilmesi gibi birçok fayda sağlamaktadır.

Yangın mahallinde şekil 9'daki gibi kablosuz kulaklık teknolojisi kullanılmasıda hız ve taktiksel manevralara elverişli bir zemin sağlamaktadır. Diğer taraftan uçaklarda kullanılan kara kutuya benzer bir yapının kullanılması itfaiye araç olaylarının gerçek zamanlı olarak izlenmesi, kaydedilmesi ve raporlandırılması açısından önem teşkil etmektedir. NFPA 1901'in 2016 yılı son baskısında araç veri kayıt cihazı standart bir madde olarak eklenmiştir. Bu teknolojinin kullanılması ile araç operatörünün performansını üst seviyeye çıkartmanın yanısıra trafik kazalarında yasal korunma sağlamaktadır. NFPA 1901 'deki diğer bir dikkat çeken husus ise itfaiyecinin kemer takmadığı zaman sistemin uyarı vermesidir. 


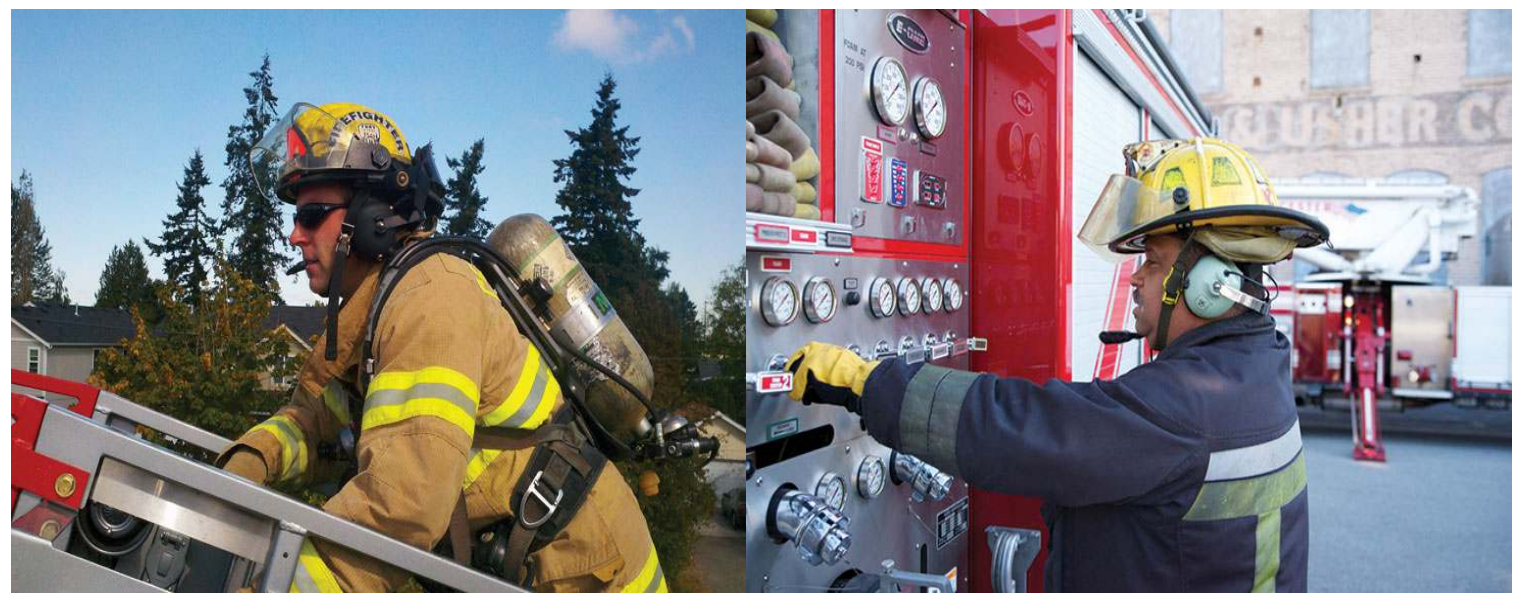

Şekil 9. Kablosuz kulaklık teknolojisi [8]

The Emerec Devs (Driver Enhanced Vision System) adı verilen gelişmiş sürücü görüş sistemi sürücüye kötü görüş şartlarında destek verir. Örnek verilecek olursa endüstriyel tesis, havaalanları ve askeri tesisler gibi önem arz eden yerlerde hassas navigasyon teknolojisi kullanılarak ulaşım yerine zaman kaybetmeden varılmasını sağladığı gibi GPS sinyalleri ile araçlar harita üzerinde gerçek zamanlı olarak izlenilmektedir. İtfaiye sürücüsünün kötü hava şartlarında (duman, sis ve aşırı karanlık ortamlarda) kızılötesi kamera özelliği olan görme arttırıcı bir bileşeni bulunmaktadır. (Şekil 10)

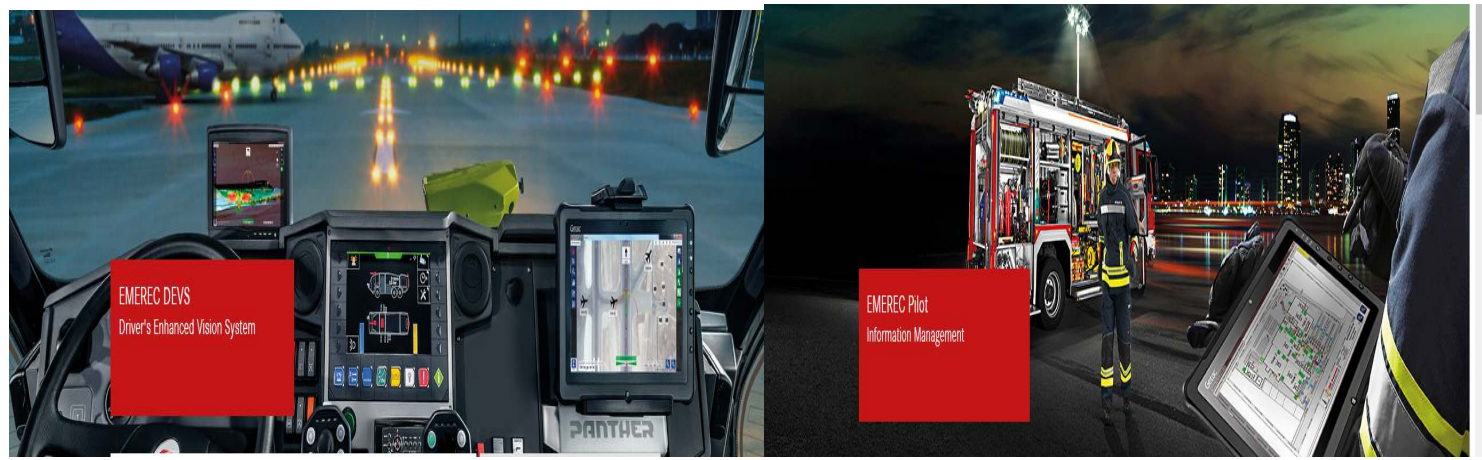

Şekil 10. Geliştirilmiş sürücü görüş sistemi (navigasyon, izleme ve görüntü sistemi) Sürücü kabinine monte edilen sistem tablet pc ile çalışma özelliğine sahiptir [9]

Birçok özel araçta ve yolcu taşıtında hareket halindeki aracı önceden algılayıcı sistem operatörü uyarmakta ve arka manevra çarpışmalarını da önleyebilmektedir. Radar tabanlı teknoloji kullanarak aracın diğer araçlara göre hızı kontrol edilerek olası çarpmalara karşı frenleme yapılmaktadir [10] [11] [12] [13]

\subsection{Dijital Lanslar (Yeni Nesil)}

İtfaiyecilerin akan suyun kullanımının elverişli olmadığı veya pratik olmadığı mekanlarda eğitilmesine olanak sağlayan bu lans sistemi gerçek otomatik nozullarla yapılmaktadır. Tamamen şarjlı (dolu) bir hortum ağırlığına sahip olmaktadır.

Lans, gerçek bir alevle temasa girdiğinde otomatik olarak kızılötesi ışık ve lazer yaymaktadır. 
İtfaiyeciler yangını sadece uygun hortum tekniği ve açısı kullanıyorsa yangın söndürülmektedir. Sistem dolu hortum deşarjını simüle eden ses sistemi ile kullanıcıya canlı yangın ortamı sağlamaktadır[14].
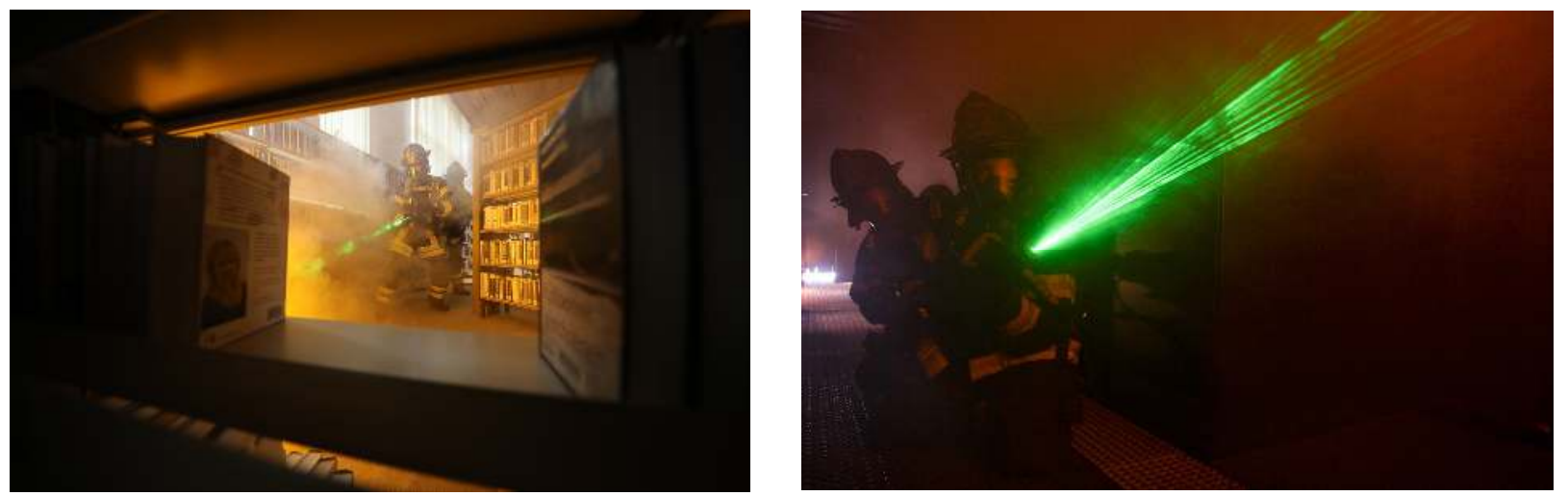

Şekil 14. Dijital Lans ve Dijital Lans ile Müdahale [14]

\subsection{Yangın Barınakları}

Yangın ortamında kalınabilecek yerlerde kişiye alevlerin kötü etkisinden kurtarabilecek yangın barınakları pratik olarak yatay ve dikey şekilde çanta şeklinde taşınabilmektedir. Orman yangınlarında alevler rüzgarın etkisiyle muazzam şekilde ilerleyebilmektedir. Çanta içerisinden çıkartılan barınak yangınlara karşı koruyucu materyalden yapılmıştır.

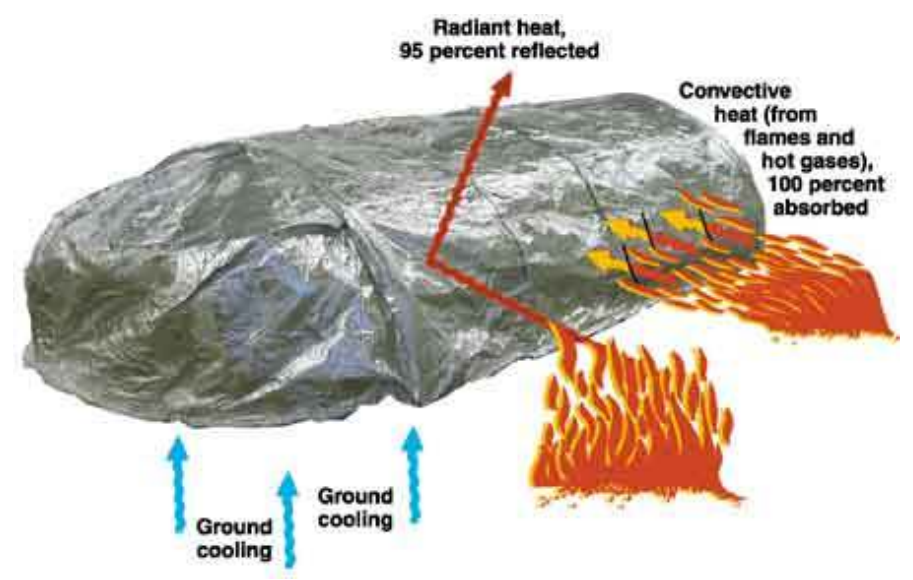

Şekil 15. Yangın Barınağı radyan ısıyı yansıtır ve konvektif ısıyı emer

\section{Sonuçlar}

Yangının kullanılması ve kontrol edilmesine yönelik yöntem ve araçların geliştirilmesi, insanlık için kritik öneme sahiptir. Teknoloji geliştikçe yangın riskleri artmakta bununla beraber alınacak önlemlerde buna parallel olarak gelişmektedir. Son dönemlerde artan yangınlar analiz edildiğinde kayıpların azalması yangın konusunda yenilikçi sistemlerin itfaiyelere kazandırılması ile olacağı düşünülmektedir. 


\section{Kaynaklar}

[1] Drucker, F. Peter, Innovation and Entrepreneurship, Harper\&Row Publisher Inc., New York; 1985.

[2] İnovasyon ve Risk Yönetimi, Marmara Üniversitesi Risk Yönetimi Ders Notları, Doç.Dr. Özalp Vayvay Marmara Ün.Müh.Fak.End.Müh.Böl.

[3] http://www.bilimgenc.tubitak.gov.tr/makale/nasadan-itfaiyecilerin-hayatini-kurtaracakyapay-zeka-yazilimi, NASA'dan İtfaiyecilerin Hayatını Kurtaracak Yapay Zekâ Yazılımı, Dr.Tuba Sarıül

[4] https://www.smithsonianmag.com/innovation/nasa-developed-ai-could-help-savefirefighters-lives-180960398/.

[5] http://www.news.gatech.edu/2016/02/29/emergencies-should-you-trust-robot, alındığ1 tarih: 01.05.2018.

[6] http://www.dailymail.co.uk/sciencetech/article-2124348/Would-want-saved-THIS-U-SNavy-creates-terrifying-robot-fireman.html. 01.05.2018

[7] http://navylive.dodlive.mil/2015/02/04/making-sailors-saffir/ 02.05.2018

[8] http://www.fireapparatusmagazine.com/articles/print/volume-21/issue-10/features/wirelesscommunications-making-great-strides-in-fire-service.html

[9] https://www.rosenbauer.com/en/svc/rosenbauer-world/products/mobile-informationmanagement/emerec-devs

[10] https://www.firerescue1.com/fire-products/fire-apparatus/articles/370667018-8-gamechanging-apparatus-trends-from-2017/ 02.05.2018

[11] Fire Apparatus Manufacturers Association. "The Future of Fire Apparatus and Emergency Equipment.”Availableat:https://fama.org/wpcontent/uploads/2015/09/1441306255_55e896 $8 \mathrm{fa} 7 \mathrm{fb} 0 . \mathrm{pdf}$

[12] SetCom Corp. Available at: www.setcomcorp.com/fire.html

[13] Fire Research. Available at: www.fireresearch.com/

[14] https://www.lionprotects.com/firefighter-training-props-digital-nozzle 